\title{
Non-Vital Root Submergence for Preservation of Socket in an Adolescent - A Rare Case Report
}

\author{
Neeta S. Padmawar ${ }^{1}$, Rachita G. Mustilwar'2, Viddyasagar P. Mopagar³, \\ Sourabh R. Joshi ${ }^{4}$, Vinay H. Vadvadgi ${ }^{5}$, Gowri Pendyala ${ }^{6}$ \\ 1,3,4 Department of Paediatric \& Preventive Dentistry, Rural Dental College, Pravara Institute of Medical Sciences \\ (Deemed to Be University), Loni, Maharashtra, India. 2, 5, 6 Department of Periodontology, Rural Dental College, \\ Pravara Institute of Medical Sciences (Deemed to Be University), Loni, Maharashtra, India.
}

\section{INTRODUCTION}

Complex crown root fracture has been reported to be $5 \%$ among the traumatic injuries to permanent teeth. In children, when fracture line extended sub gingivally, the treatment option remained was the extraction of tooth. This extraction led to alveolar bone loss and compromised the outcome of final prosthesis. Root submergence is one of the treatments options which can prevent bone loss and prepare future pontic site in a better way. In children, this technique can prevent not only bone loss but also the occurrence of space loss and development of tongue thrusting habit.

Crown-root fracture is defined as a fracture involving enamel, dentin and cementum. It is reported in about $5 \%$ of dental trauma to young children where root completion has not occurred..$^{1}$ Treatment of these complex tooth fractures in aesthetic zone in growing age is always challenging for the paedodontists. The treatment should not interfere with the growth and development.

Depending upon the extension of the fracture line which can result in exposure of the pulpal tissue, the crown-root fracture can be divided into two groups: complicated and uncomplicated. ${ }^{2}$ Treatment options in cases of complicated crownroot fractures are complex, and require a multidisciplinary approach.

Dental traumatology guideline and American Academy of Paediatric Dentistry has suggested fragment reattachment, orthodontic or surgical extrusion of apical portion followed by post placement, root submergence and extraction. ${ }^{3}$ Factors like extension and direction of fracture line, pulpal involvement, tooth maturity and the length of root remaining in the alveolus govern the treatment choice. ${ }^{4,5}$ Among above mentioned factors, position of facture line is the most important. As in case of subgingival facture line, risk of bacterial contamination is present and further this may result in gingival inflammation. ${ }^{6}$

When crown root fracture to permanent tooth occurs in mixed dentition period, goals of treatment are to preserve the tooth in arch without disturbing the growth \& development of root and arch. But in case of complicated crown root fracture, when extraction is the only choice of treatment, future complications like space loss, crowding, habits like tongue thrusting and importantly loss of alveolar bone height should be kept in mind. Goals of treatment plan in such cases should be elimination of space loss, development of deleterious habit and maintenance of alveolar ridge for future pontic or implant site. Root submergence is the technique with which we can achieve these goals, keeping this in mind this case was planned and reported.
Corresponding Author: Dr. Neeta S. Padmawar Department of Paediatric \& Preventive Dentistry, Rural Dental College, Pravara Institute of Medical Sciences (Deemed to Be University), Loni (BK) - 413736, Maharashtra, India,

E-mail: opneeta23@gmail.com

DOI: $10.14260 / \mathrm{jemds} / 2021 / 304$

How to Cite This Article:

Padmawar NS, Mustilwar RG, Mopagar VP, et al. Non-vital root submergence for preservation of socket in an adolescent - a rare case report. J Evolution Med Dent Sci 2021;10(19):1448-1450, DOI: $10.14260 /$ jemds/2021/304

Submission 26-12-2020,

Peer Review 10-03-2021,

Acceptance 16-03-2021,

Published 10-05-2021.

Copyright $(2021$ Neeta S. Padmawar et al. This is an open access article distributed under Creative Commons Attribution License [Attribution 4.0 International (CC BY 4.0)] 


\section{PRESENTATION OF CASE}

A twelve-year-old healthy boy reported to Outpatient Department of Paediatric \& Preventive Dentistry complaining of pain and discomfort in lower anterior region. Intra-oral examination revealed presence of Ellis \# III fracture in relation to permanent mandibular right lateral incisor (\# 42). History revealed that the trauma occurred 1 week back while playing in the school. Intra-oral periapical radiograph (IOPA) revealed complete root formation of \# 42, periodontal space widening was also seen. Root canal treatment (RCT) was advised and explained to the parents.

\section{DISCUSSION OF MANAGEMENT}

After obtaining consent from the parents, root canal was started under local anaesthesia (2\% Lignox ${ }^{\circledR}$ - $2 \%$ lignocaine with adrenaline, 1:80,000). In first visit, access opening and biomechanical preparation with hand Protaper files till \# F2 (Dentsply Protaper universal) was carried out under OptraDam. Patient was prescribed anti-inflammatory tablet \& recalled after 2 weeks. In second visit, intra-oral examination revealed loose mobile fragment of the crown of \# 42 and history revealed incidence of trauma again in between the two visits. Intraoral periapical radiograph (IOPA) showed fracture line extending till cementoenamel junction sub gingivally (Figure 1). Root submergence was planned combined to preserve the alveolar bone height for future implant prosthesis. Parents gave consent for change in treatment. Obturation with $6 \%$ gutta percha (Dentsply Protaper universal gutta percha) and Ah Plus (Dentsply) sealer followed by glass ionomer cement (type II, GC Fuji, Japan) restoration was done.
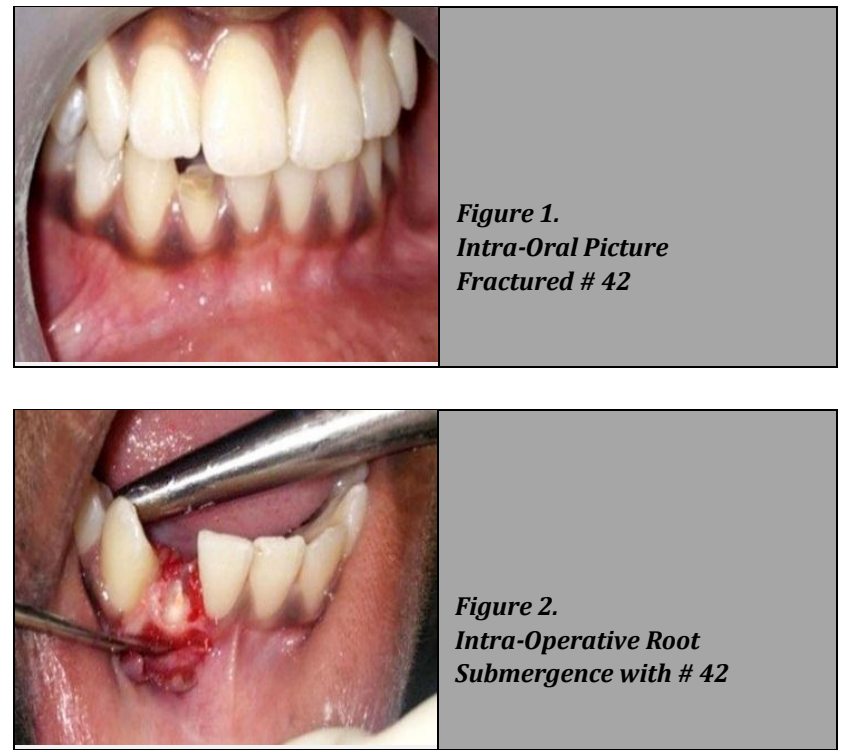

After achieving anaesthesia, using inferior alveolar nerve block with $2 \%$ lignocaine, full thickness flap was raised buccally and lingually by giving crevicular incision and releasing incisions with blade \# 12, 15. Flap was raised, fracture segment was removed and sharp margins were smoothened (Figure 2). Irrigation with normal saline and restoration with type II GIC (Fuji, Japan) was done. After approximation of flaps, sutures were given with 4.0 Vicryl (Ethicon Inc.) resorbable suture material (Figure 3). Patient was kept under observation and followed-up. After one month (Figure 4), complete healing was occurred, in same appointment impression for removable prosthesis was made. After one-week, single tooth removable partial denture with soft liner (GC Fiji, Japan) was delivered (Figure 5). Follow-up of every 3 months was advised (Figure 6). First follow-up was done, no abnormal findings were observed, and patient was still under observation.
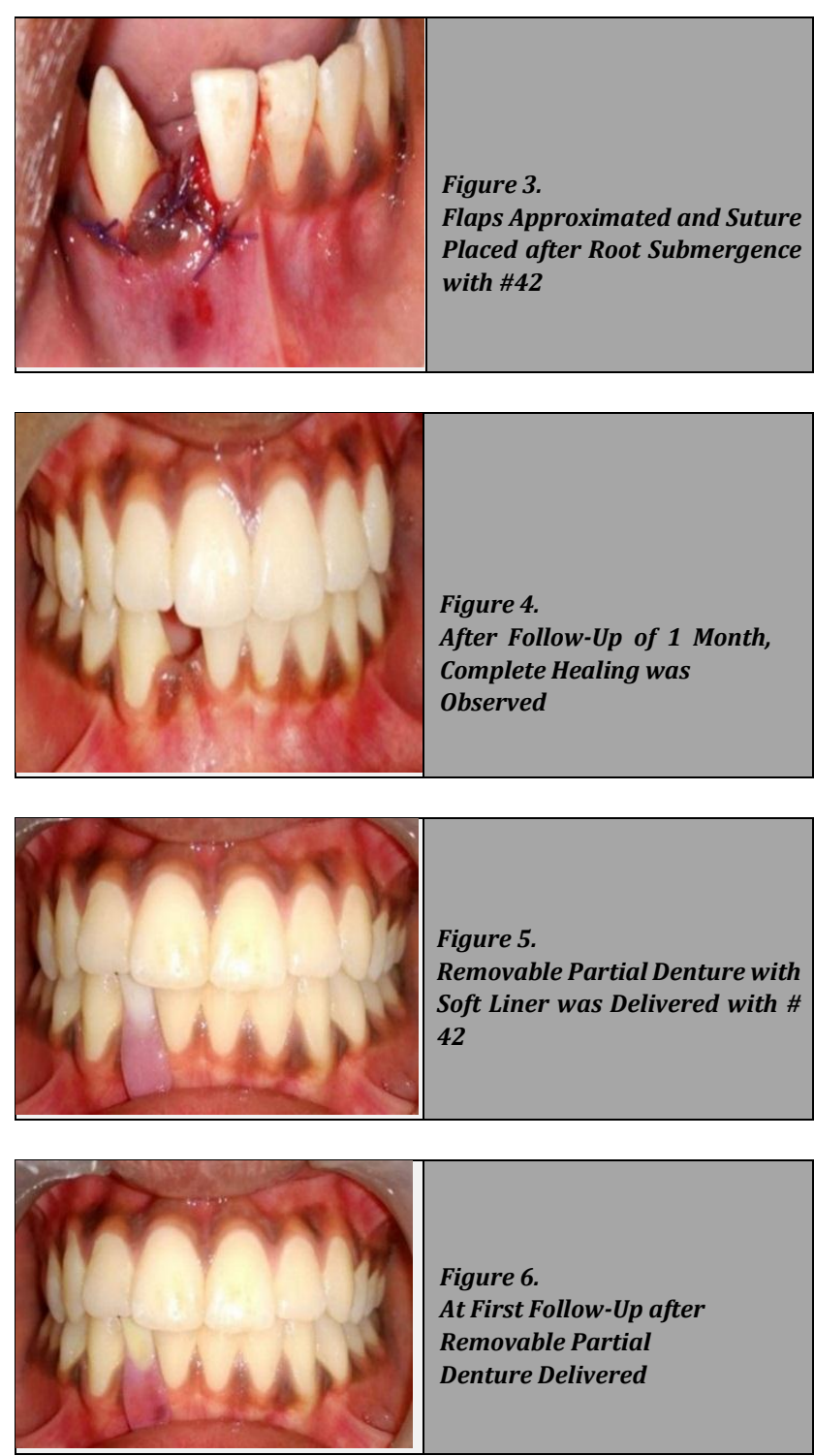

\section{DISCUSSION}

Resorption of remaining alveolar ridge was inescapable consequence following the extraction of a tooth. An average rate of resorption of the residual ridge after tooth loss has been estimated to be $0.5 \mathrm{~mm}$ per year.7,8 It has been shown that the mandibular ridge resorbs approximately four times more rapidly than does the maxillary ridge. Resorption of remaining alveolar ridge compromises the outcome of final prosthesis. 7,8

Intentional root submersion was published by Bjorn in 1961 for first time. He introduced it as an adjuvant to prevent 
residual alveolar ridge resorption to improve the retention and resistance of a complete denture. ${ }^{9}$

This technique is not advised where root caries, external root resorption and periapical pathology is present. ${ }^{10}$ In our case, root was healthy without any periapical pathology making it possible suitable for root submergence procedure.

Factors like size of occlusal table, amount of cortical plate covering submerged root and presence or absence of undercuts will contribute to the outcome of root submergence technique. Smaller occlusal table have better prognosis as approximation of flap is easy and primary healing is easily achieved, retained roots should have adequate coverage of cortical plate and teeth should not have undercuts as it will compromise retention of the denture. ${ }^{11}$ In present case, submergence was carried out on mandibular lateral incisor which has small occlusal table and has lingual inclination which provides increased thickness of buccal cortical plate and it was free from any undercuts making it favourable for root submergence procedure.

Methods advocated for root submergence are - (1) root submergence with vital pulp (2) endodontically treated root submergence and (3) intentionally done replantation followed by submergence. In this method endodontic treatment was carried out prior to replantation outside the oral cavity. ${ }^{12,13}$ Final outcome of these three techniques are different. In first method osteodentin covered the vital pulp of submerged root where as in second method bone formation observed over endodontically submerged root. Ankylosis was final result in intentionally replanted submerged root. Healing pattern in all three techniques of root submergence are different. In first method / technique osteodentin covers remaining vital pulp followed by bone formation. Bone formation has occurred over endodontically treated submerged roots. In third technique ankylosis is the final result after submergence.12,13

Howell advised submergence of endodontically treated root with no periapical pathology as vital pulp may increase the risk of developing periapical infection. ${ }^{14}$

In children where root growth has not completed and pulp is vital, vital root submergence is advised. In literature also, reports of vital root submergence in children have been reported. But in our case root closure was completed and endodontic treatment was started so we choose second technique of endodontically treated root submergence.

Removable partial denture was delivered to maintain the space, improve aesthetics and prevent development of intentional tongue thrusting habit. This denture will be replaced depending upon the growth and development of the mandible.

With objective of maintaining height and width of alveolar bone and continued growth of jaws, we chose this treatment option. ${ }^{15}$ Follow up showed satisfactory results.

\section{CONCLUSIONS}

Preservation of alveolar bone and preparing it for future implant site should be kept in mind during the treatment of complex subgingival tooth fracture. Root submergence is the treatment option for this purpose. But long-term follow-up of patient till the patient reaches maturity is required.

Financial or other competing interests: None.

Disclosure forms provided by the authors are available with the full text of this article at jemds.com.

\section{REFERENCES}

[1] Fariniuk LF, Ferreira EL, Soresini GC, et al. Intentional replantation with 180 degree rotation of a crown-root fracture: a case report. Dent Traumatol 2003;19(6):3215.

[2] Robertson A. A retrospective evaluation of patients with uncomplicated crown fractures and luxation injuries. Endod Dent Traumatol 1998;14(6):245-56.

[3] Diangelis AJ, Andresasen JO, Ebeleseder KA, et al. International association of dental traumatology guidelines for the management of traumatic dental injuries: 1. fractures and luxations of permanent teeth. Dent Traumatol 2012;28(1):2-12.

[4] Andreasen JO. Etiology and pathogenesis of traumatic dental injuries. A clinical study of 1298 cases. Scand J Dent Res 1970;78(4):329-42.

[5] Naudi AB, Fung DE. Tooth fragment reattachment in multiple complicated permanent incisor crown-root fractures: a report of two cases. Dent Traumatol 2008;24(2):248-52.

[6] Andreasen JO, Andreasen FM, Andersson L. Textbook and color atlas of traumatic injuries to the teeth. $4^{\text {th }}$ edn. Oxford, England: Blackwell Munksgaard 2007:314-36.

[7] Bjorn H. Experimental studies on reattachment. Dent Pract 1961;11:351-4.

[8] Bjorn H, Hollender L, Lindhe J. Tissue regeneration in patients with periodontal disease. Odontol Revy 1965;16(4):317-26.

[9] Casey DM, Lauciello FR. A review of the submerged-root concept. J Prosthet Dent 1980;43(2):128-32.

[10] Comut A, Mehra M, Saito H. Pontic site development with a root submergence technique for a screw retained prosthesis in the anterior maxilla. J Prosthet Dent 2013;110(5):337-43.

[11] Delivanis P, Day O, Esposito C, et al. Clinical considerations for root-submergence procedures. J Prosthet Dent 1980;43(5):487-90.

[12] Johnson D, Kelly J, Flinton R, et al. Histologic evaluation of vital root retention. J Oral Surg 1974;32(11):829-33.

[13] O'Neal RB, Gound T, Levin MP, et al. Submergence of roots for alveolar bone preservation. I. Endodontically treated roots. Oral Surg Oral Med Oral Pathol 1978;45(5):803-10.

[14] Howell F. Retention of alveolar bone by endodontic root treatment. Seminario Anual de1 Grupo de Estudios Dentales USC de Mexico Vol. 23. 1970.

[15] Malmgren B. Decoronation: how, why and when? J Calif Dent Assoc 2000;28(11):846-54. 